(D) Lütfi Telci

Geliș Tarihi/Received : 20.08.2020

Kabul Tarihi/Accepted : 21.08.2020

(C) Telif Hakkı 2020 Türk Yoğun Bakım Derneği Türk Yoğun Bakım Dergisi, Galenos Yayınevi tarafından yayınlanmıştır.

Lütfi Telci

Acıbadem Sağlık Grubu, Anesteziyoloji Kliniği,

Istanbul, Türkiye

Lütfi Telci (凷),

Acıbadem Sağlık Grubu, Anesteziyoloji Kliniği,

Istanbul, Türkiye

E-posta : telci@istanbul.edu.tr

Tel. $\quad$ : + +902126318767

ORCID ID : orcid.org/0000-0001-6838-5670

\section{Beklenen Ölüm}

\section{Expected Death}

ÖZ Her toplumun farklı adetleri/gelenekleri vardır. Toplumun bireyleri bu adetlere/geleneklere; benimseme, kabullenme ve reddetme biçiminde tepki gösterirler. Nezaket kurallarının en geçerli hale ulaştığı noktada, ahlaki değerler nezaket kurallarıyla yarışır.

Anahtar Kelimeler: Ölüm, yoğun bakım, yargı, tıbbi vasiyet

ABSTRACT Every society possess different customs and traditions, and its members are free to either accept or reject them. However, when the rules of kindness reach their optimal validity, moral values compete with the rules of courtesy.

Keywords: Death, intensive care, judgment, medical will

\section{Giriș}

Her toplumun farklı adetleri/gelenekleri vardır. Toplumun bireyleri bu adetlere/geleneklere; benimseme, kabullenme ve reddetme biçiminde tepki gösterirler. Hartland-Swan toplumda var olan adetleri/gelenekleri önem sırasına göre sınıflandırır.

-En önemli adetleri/gelenekleri belirleyen kurallar sonunda yasalara dönüşür ve toplumun tüm bireylerini bağlayan yasal yükümlülükleri oluşturur.

-Orta derecede toplumsal önem taşıyan adetleri/ gelenekleri belirleyen kurallar, toplumun ahlak kuralları çemberini oluşturur ve toplum bireylerinin ahlak anlayışına yön verir.

-En az derecede toplumsal önem taşıyan adetleri/ gelenekleri belirleyen kurallar ise toplumun nezaket sınırlarını belirler (1).

Bu sınıflandırmayı toplumun gelişmişlik göstergelerinde kullanabilir; nezaket, ahlak ve yargıda hakkaniyet üçlemesiyle ideal toplumu tanımlayabiliriz. Nezaket kurallarının en geçerli hale ulaştığı noktada, ahlaki değerler nezaket kurallarıyla yarışır. Yargı yolu ile adalet arayışına ihtiyaç duyulmayan, içinde yaşadığı topluma yük olmayan, üretken insanların çoğunluk oluşturduğu toplumu hayal etmeyi iyimser bir bakış açısıyla sürdürelim.

Yargıda adaleti hedefleyen hukuk devletlerinde, kazanılmış ve kanun ile belirtilmiş haklar önemli olmakla birlikte kazanılmış bu hakları tartışmaya açan yeni görüşler her daim yeniden gündeme alınabilir. Bunun sonucunda medeni kanun ve ceza hukukunda kriz düzeyinde sorunlar çıkabilir. Çıkmaza giriliyor gibi görünse de hukukun üstünlüğünde devreye derhal içtihatlar ve hukuk felsefesi girer ve çözüm sağlanmış olur (2).

Nezaket, ahlak (etik) ve hukuk değerleriyle yetiştiğimiz toplum içinde bize düşen görevleri yerine getirmeliyiz. Ters düştüğümüz kavramlara itiraz etmeyi, karşı tavır almayı yeterli görmemeliyiz. Felsefi arayışlara katılmak, mütevazi bir düzlemde felsefe yapmak, kavram/kavramlar ortaya atmak gibi arayışlarımız olmalıdır. 
Yoğun bakım eğitimi içinde, önemi her geçen gün katlanarak artan "yoğun bakım etiği", bu nedenle çok özeldir. Günlük uygulamalarımız içinde sürekli tartışılan ve bize derinlik kazandıran yoğun bakım etiği, yoğun bakım ekibi içinde yer alan herkesin bilgisini tekrarlayarak artırdığı ders niteliğindedir. Ekip, tartışılan etik sorunlar varlığında bu tartışmaya katılma, katkı yapma, karşı durma veya farklı boyutlara taşıma konularında sürekli sorumluluk almalıdır. Etik sorunlara eğilmeden ekibin günlük işleyişleri sonlanamaz. Yoğun bakım biliminin eğitici ve öğrencileri olarak, yoğun bakım etiğini tek başlık halinde derinlemesine tartışmak ve kavramları pekiştirmek için, "Yoğun Bakımların Akılcı Kullanımı" sempozyumlarını yararlı ve gerekli buluyoruz. Türk Yoğun Bakım Derneği'nin 2 Kasım 2019 tarihinde gerçekleştirdiği "3. Yoğun Bakımların Akılcı Kullanımı" sempozyumunda "Yaşam Sonu Kararlar" başlığı etik, hukuk ve felsefe yaklaşımlarıyla irdelenmiş, nedir? / niçin? / ve nasıl? sorularının yanıtları aranmıştır.

Yaptığınız tüm tedavi ve bakıma rağmen hastanızı kaybettiğinizde hatırlamanız ve kutsal görevlerinizi aynı heyecan ve istekle sürdürmeniz için sunacağım felsefi başlık, Heidelberg Üniversitesi anatomi bölümü giriş kapısının üstünde yer almaktadır.

"Hic gaudet mors succurrere vitae"

"Burada ölüm, yaşama memnuniyetle destek verir" (3).

"Burası ölümün yaşama severek destek verdiği yerdir" [Yard. Doç. Dr. Ayşen Yavru, çeviri önerisi, 2020] .

Uluslararası ortamlarda sıkça tekrarlanan bir gerçek vardır. Ülkelerin sağlık sistemlerine genelde sınırlı kaynaklar sunulur. Bu gerçek yoğun bakım servisleri için de geçerlidir. Yoğun bakım olanaklarımızın da sınırlı olduğu ve olanakları akılcı kullanmakla yükümlü olduğumuzu unutmamalıyız. Bu düşünceyi benimsemek, destekleyen tarafta yer almak yeterli değildir. Bununla yetinmek, görevimizi eksik yaptığımız anlamına gelmeli ve bizi huzursuz kılmalıdır. Sürekli felsefi arayışlar içinde olmalıyız. Felsefenin güncelliğinden yararlanarak kavramlar geliştirebileceğimize inanmalıyız. Doğal olarak toplum da bizden bunu bekler, beklemelidir de.

Yoğun bakımda yaşarken sıkça yaptığımız yaşamın özüne yoğunlaşma egzersizlerine geri dönerek, Aristoteles'ten alıntıyla yaşam tarzlarını tanımlayalım. Aristoteles'in özgür insanında üç yaşam tarzı bulunur.

-Haz arayışındaki yaşam (hedone),

-Güzel ve soylu edimler üreten yaşam (bios politikos),

-Hakikati düşünmeye adanmış yaşam (bios theoretikos) (4).
Yaşamın temel gereksinimlerini içeren bu tanımlamanın içinde yer alan "bios politikos", yaşam için zorunlu olan çalışma ve para kazanmayı ifade eder. Toplum için yararlı ve gerekli işlerin yapılması, onurun korunması ve erdemli (etik) kalmanın olağan sayıldığı ortamlardaki çalışma biçimini ifade eder "bios politikos".

Hangi koşulda ve ne zaman olursa olsun çalışmak zamanı tüketir. Aristoteles'in yaptığı sınıflandırma içinde en yüksek mertebedeki yaşam biçimi, derin düşünceye adanmış yaşam "bios theoretikos"dur. Antik zamanda derin düşünceye adanmış yaşam kutsanırken, çalışmaya adanmış yaşam bir dereceye kadar hor görülürmüş (4). Günümüzde çalışmadan sürdürülebilecek bir yaşam biçimini konuşmak anlamsızdır. Çalışmanın değer kazanması ortaçağın sonlarına doğru olmuştur.

Varlığımıza anlam katacak çalışma dönemini içine alan "aktif yaşam" zorunludur. Çalışmayan veya çalışamayanın yaşama tutunma olanağı tehdit altındadır. Bu tehdit, koşuşturmaları ve iş olanaklarını koruyabilme telaşını getirir. Gerginliklerle dolu zamanların hüküm sürdüğü yaşam biçimi ortaya çıkar. "Zaman" kavramının değer yargıları değişmiş̧tir. Süratle iş bitirme stratejileri geliştirildikçe "zaman" krizi ortaya çıkar ve insanlar bu kriz içinde boğulmamak için çok çaba sarf eder. Çalışma dönemimizde önümüze çıkacak "zaman" krizlerine çözüm aranmalı ve düşünsel "zamana" mutlaka yer açılmalıdır. Deneyimin zamanla bağı kesindir. Zamanda uzayıp giden deneyim, deneyimleyen öznenin kendini bulmasına yardım eder. Bu başarılamaz ise "zamanı aralıksız çalışarak tüketen" emek işçisi konumuna gelinir. Gelişimi sağlayan "geçmiş ile gelecek arasında yer alan ve geniş bir süreyi kapsayan deneyimdir"(4).

Yoğun bakımda geçen yaşamı, alandaki hekimlerin yaşam izdüşümünde irdelersek, farklı iki evreyi görebiliriz. Birinci evre asistanlık eğitimine başladığımız anda başlar, uzman olduğumuzu fark ettiğimiz ana kadar sürer. Ikinci evre kıdemli uzmanlığımızın sorumluluğunu hissettiğimiz anda başlar, mesleğimizi noktaladığımız anda biter. Birinci evre öğrenme, ezberleme, koşuşturma, kayıt altına alma, her şeye yetişme ve deneyime tanık olma gibi eğitimin vazgeçilmez "yoğun çalışma dönemini (vita activa)" kapsar. Bu dönemde yoğun bakım uzman adayı olanlar ve genç uzmanlar, yoğun aktif çalışma baskısı altında oldukları için, yaşadıkları zaman içinde "düşünsel yaşama (vita contemplativa)" ayıracak zamanı pek bulamazlar. Adaylardan bazıları, düşünsel yaşama ayıracak zamanı bulmak için özel teknikler geliştirir ve akıllı çözümler üretir. Düşünsel yaşama zaman ayıranların yoğun 
bakım eğitimi daha başarılı olur, düşünsel yaşama geçme alışkanlıkları artar ve bağlı olarak klinik deneyimleri de kalıcı hale gelir.

Eğitim sürecindeki hekim ve hemșirenin yoğun bakım yaşamları "aktif yaşamla (vita activa)" başlar ve bitebilir. "Düşünsel yaşama (vita contemplativa)" geçişi kendilerinin başlatabilmesi enderdir. Eğitim gördükleri yoğun bakım servis eğiticilerinin "düşünsel zamana" ayırdığı zaman ve yaptığı yatırımlar oranında "düşünsel zamana" geçişleri kolaylaşır ve "düşünsel zamana" ayrılan mesaileri artar.

Sorumlu uzman konumuna geçiş ile başlayan ve mesleğimizi noktaladığımız anda biten ikinci evrede, yoğun bakımdaki yaşam neredeyse "düşünsel yaşam (vita contemplativa)" ile tamamlanır.

Sorumlu uzman yapmış olduğu tedavileri, takip ettiği protokolleri, elde ettiği sonuçları, başarılarını, başarısızlıklarını, nedenleri ve niçinleri gün boyu, gün sonu sorgular ve izler. Yirminci yüzyıla damgasını vuran "kanıta dayalı tıp", yoğun bakımda hala geçerliliğini koruyan "gözleme dayalı tıp" ile çekişmesini sürdürürken, sorumlu uzmanın "gözleme dayalı tıbba" esareti devam etmektedir. Sürekli ve kesintisiz izlediği veri akışlarını yorumlar ve acabalar arasında kendisini "düşünsel yaşamın" ortasında bulur. Düşünsel yaşamındaki etik değerlendirme ve felsefi arayışların katkıları ile hastaların prognozları hakkında bir fikir oluşturur. Günlük bilgilendirme işi, bu değerlendirmelerin sonucunda ortaya çıkan gerçeklerin hasta yakınlarına aktarımından ibarettir. Etik değerlendirmelerin her gün yapılması yoğun bakım ekibini, elim sonuçların görülebileceği günlere hazır hale getirir. Aklın kılavuzluğunda erdemli-etik hareket etmekle yükümlü yoğun bakım ekibi, günlük vizitler sonrasında her gün sınava girer ve geçer. Bu sınavlar geçilemez ise yoğun bakım sınavının da geçilemeyeceği bilinci ekibin düşünsel yaşamına yerleşmiştir.

Etiğin ilkelerine hakim olunduğunda, her soruna cevap verebilmenin iç huzuruna kavuşuruz. Her koşulda etik kuralların içinde kalacağım diyen sorumlu uzman bilmelidir ki, örnek ile gerçek birbirinden çok farklıdır. Etik sınırları kuvvetle savunanlar, örnek ile gerçek arasındaki gerilime katlanmaya hazır olmalıdır (3).

Tıp etiği hastayı, hasta yakınlarını ve toplumu ilgilendiren, tıbbi bilgileri sorgulayan dinamik bir disiplindir. Tıbbın ilerlemesi bazı etik sorunlara çözüm getirirken, yeni ve ilk kez karşılaşılacak özgün etik sorunlar doğurur. Etik görüşlerin felsefi, hukuki ve teolojik bağları ayrı ayrı ele alınmalıdır. Antik Çağ'dan günümüze kadar, felsefeden etiğe, felsefi etikten tıbba çok katkı olmuştur. Tıp etiğinin temel konuları içinde yer alan, hasta-hekim ilişkisi, acı, hastalıkların tedavi biçimleri ve klinik araştırmalar her gün etiğin kontrol kapılarından geçer. 1990'lı yıllarda başlayan ve günümüze kadar hız kesmeden süren, ölüme karşı tutumların etik yönden değerlendirme çalışmalarında, birçok ülkede benzer kararlar alındığı görülmüştür. Çalışmaların ortaya koyduğu sonuçlar bizleri ortak bir noktaya getirmiş olsa bile, uluslararası ve ulusal klinik araştırmaların sürdürülmesine duyulan gereksinim devam edecektir. Yoğun bakım camiamızın da yer aldığı klinik araştırmalar devam ede dursun, deneyimlerimin boyutuna uygun görüşlerimi aktarmak istiyorum.

Kierkegaard der ki, insan yaptığı seçimlerle varlığını inşa eder ve seçilmiş olan varoluş tarzları yaşamı belirler.

Insanlar;

-Estetik varoluşta kendi için iyiyi

-Etik varoluşta başkası için iyiyi

-Toplumcu varoluşta toplum için iyiyi

seçerler (5).

Hekim olduğumuz gün etik varoluşta kalacağımıza yemin ettiğimize göre, diğer veya başka şıkları tanımlayan yollar bize kapanmıştır. Etik sorumluluğumuz var ve en doğru olanı yapmak üzere eğitildik. Sorumluluğumuz gereği kararlar veririz ve sorumluluğumuzu başkalarına devredemeyiz.

Etik kararların alındığı ortamlarda erdemli yaşam tarzı sürdürülür. Erdemli yaşam tanımını Spinoza'dan alıntı yaparak yazalım. "Bizim için mutlak anlamda erdemli hareket etmek sadece aklın kılavuzluğunda hareket etmek, yaşamak ve varlığımızı sürdürmek demektir". Bu tanımlamadan almamız gereken kalıcı emir "aklın kılavuzluğu"dur (6).

Üçüncü düzey çoğul disiplinli kapalı sistem yoğun bakım servislerinde ölüm oranları, diğer servislere oranla yüksek olur. Bu nedenle servis içinde ve dışında, servisin günlük işleyişlerine felsefeden yararlanarak etik sınırlar çizeriz. Felsefeyi "ölüme hazırlık" olarak tanımlayan Sokrates ve Cicero ile giriş yapmayı size de önerebilirim (7). "Ölümün, felsefenin gerçek ilham perisi veya esinleyici gücü" olduğunu söyleyen Schopenhauer'ın yazdıklarını da okuduktan sonra, artık felsefi okumaların önünü alamazsınız.

Yoğun bakım uzmanları, tüm özgür insanlar gibi ölümü en az düşünür. Yaşamı temel alır, yaşatmak için uğraşırız. Spinoza'dan alıntılı "özgür insan, yani aklın buyruğuna göre yaşayan insan ölüm korkusuna kapılmaz" (6) düşüncesini içselleştirdiğimiz için ölüm konusuna cesaretle eğiliriz. Ek olarak Schopenhauer'ın XIX. yüzyılda ileri sürdüğü “özne için bizatihi ölüm, beyin faaliyetlerinin durması yüzünden bilincin yitip gittiği andan ibarettir" (8) düşüncesi doğrultusunda, 
bilincimiz açık oldukça ölümün felsefi boyutunu incelemeyi sürdüreceğiz. Felsefeye mecburuz çünkü, "olgu ile yapma arasında, söyleme ile söylenen arasında mesafe vardır ve bu mesafenin mevcudiyetine kendi sözümüzle tanıklık etmekten kaçmamalıyız" (9).

Nietzsche'nin "Gezgin ve Gölgesi" isimli kitabının ilk sayfasında 1880 tarihli Almanca ilk basımın kapak resmi bulunmaktadır (Figür 1).

Nietzsche o tarihte ölümü "doğal" ve "akılcı" olmak üzere ikiye ayırmıştır. Gönülsüz ölüm diye nitelendirdiği "doğal ölümü" akıllı varlığın, akıllı olmayan ve kendisine bağlanmış varlık tarafından yok edilişi olarak sunmuştur. Ölümün bilgelikle düzenlemesi ve uygulanmasına "akılcı ölüm" ismini vermişstir. 1880 yılında akılalmaz ve ahlak dışı gibi görünen, günümüzde ise yoğun bakım etiği dersi içinde yer alan ve bilimsel başlıklardan bir tanesinin teorik temellerini atmıştır (10). Nietzsche'nin yapmış olduğu tavsiyelerden kanımca yararlanmalıyız. "Insan ölmeyi öğrenmelidir" ve "ölümünüz insana ve yeryüzüne bir hakaret olmamalıdır" şeklindeki düşüncelerini "akılcı ölüm" üzerinden ele alıp yoğun bakımlarda yaşanan güncel etik sorunların çözümünde rahatıkla kullanabiliriz (8).

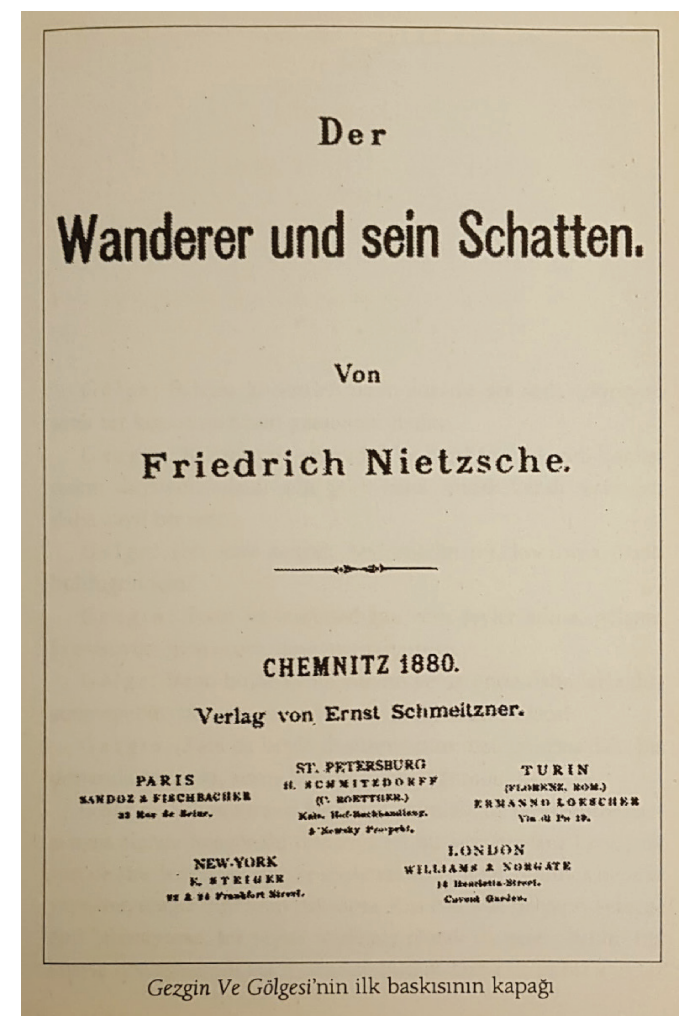

Figür 1. Nietzsche'nin "Gezgin ve Gölgesi" isimli kitabının ilk sayfasında 1880 tarihli Almanca ilk basımın kapak resmi
On dokuzuncu yüzyılda yapıımıș olan felsefi tartışmaların tıp dünyasındaki etkileri aynı yüzyı içinde görülmüştür. Beyin fizyolojisi ile ilgili deneysel çalışma sonrasında, 1866 yılında Leyden "yapay solunum yapıldığı takdirde, kafa içi basıncının artırıması ile deney hayvanlarını öldürebilmenin imkansız olduğunu" ileri sürmüştür. Ardı sıra yapılan klinik araştırmalarla varılan noktada, Horsley 1894 yılında "ölümden sonra kalbin çalışmaya devam ettiğini" bildirmesiyle, geleneksel ölüm tanısı sorgulanır hale gelmiştir. Yirminci yüzyıl tıp eğitimi içinde yer alan ünlü bilim adamı Cushing, "gerçek ölüm" meydana geldikten sonra kalbin bir müddet çarptığını, 1901 yılında öğrencilerine anlatmıştır. Gözleme dayalı tıbbın etkinliği kanıta dayalı tıp ile desteklenince, yoğun bakım servisleri ortada yok iken, "beyin ölümünün" günümüzde de geçerli olan tanısı, uluslararası alanlarda anlatılır hale gelmiştir. Ülkemizde de temel bilimci hocalarımız 1938, 1939 yıllarında "ölümü" ve "beyin ölümünü", üniversitemiz dershanelerinde anlatmışlar ve yayınlamışlardır (11).

1952 yılında yoğun bakımın tıpta yerini alması, klinik sonuçlara, bilimsel gelişmelere ve etiğe büyük katkılar yapmış ve doğal olarak yoğun bakım etiğinin ortaya çıkmasına da neden olmuştur.

On dokuzuncu yüzyılda "özne için bizatihi ölüm, beyin fonksiyonlarının durmasına bağlı bilincin yitip gittiği andır" diyen Shopenhauer'ın, bize olan katkıları hala devam etmektedir. "Kişinin gerçekleri kendi deneyim ve gözlemleri ile kavraması daha fazla öğreticidir" ve "soyut kelime ve kavramlardan oluşan bilgilerin büyük bir kısmı ölüdür" düşünceleri, kişisel deneyimin değerini bir kez daha ortaya koymaktadır. Bu düşüncelere J Dewy'nin "yaparak ve yaşayarak edinilen bilgi epistemik açıdan üstündür" (5) sözünü de eklersek, kişisel deneyimin bize kazandırdığı moralle kendimize olan güven tazelenir.

1977 yılında başlayan asistanlığımla birlikte "tanık" olma eylemlerim de başlamıştır. Tanık olma eylemlerime kişisel deneyimlerimi katarak, yoğun bakım etiğine kendi yorumumu katma cüretine gidiyorum. Etiğin hiçbir ortamda değiştirilemez kuralları olan; zarar verme, yararlı ol, adil ol, hastanın onurunu koru, bağımsız ol ve bağımsızlığını kazanamamış isen bu işe hiç karışma, başlıklarını unutmadığımı da belirtmek isterim.

Dünyanın her yerinde yoğun bakım ekibine sınırlı kaynaklar emanet edilir. Bize emanet edilen sınırlı kaynakların maddi ve manevi değerinin ölçütü ne olmalıdır? Bunu bilemiyorum. Ancak bizim herkesten daha fazla duyarlı olmamızın gerekli olduğunu çok iyi biliyorum. Bize emanet edilen sınırlı kaynaklar içinde, üstünde pek fazla 
durulmayan, dile de hiç getirilmeyen "zaman" unsurunu ele almak istiyorum. Onayımız olmadan çalınan zamanımız için, Heidegger'ın "zaman varlığın içindedir" sözünü anımsayalım ve çalmaya kalkışanlara, varlığımızdan koparılan bir parçanın değeri ölçüsünde var gücümüzle itiraz edelim. Zamanın varolan iki değeri (niceliksel-niteliksel) arasında, öncelikle niteliksel zamanımızı korumak için çaba sarf etmeliyiz (5). Bizim yaşamımızda var olan "aktif yaşam" ve "düşünsel yaşam" zaman dilimleri hastalarımızda da vardır ve bize emanet edilen değerler içindedir. Hastalarımızın tedavi süreçlerini yönetirken yaptığımız prognoz tahminleri içinde hastalarımızın "aktif yaşam" ve "düşünsel yaşam" şanslarını da değerlendirmeye almalıdır. Hasta yakınlarına yaptığımız günlük bilgilendirmelerde, hastanın bilincine yönelik prognostik değerlendirmelerimizin kapsamı içinde bu noktanın üstünde önemle durulmalıdır. Bilgilendirme odası mutlaka olmalı, bilgilendirmeler her gün yapılmalı, anlaşılır bir dil kullanılmalı, anlaşılıncaya kadar tekrarlanmalı ve beklentiler gerçekler ile örtüşmelidir. Bilgilendirmelerin sonrasında hasta yakınları, yapılması gerekenlerin tümünün yapıldığına ikna olmuş ise, bilgilendirme süreci doğru yönetilmiş ve amaca ulaşılmıştır. Bu düzeye ulaşıldıktan sonra alınacak etik kararların aktarımı yapılırsa, yoğun bakım servisimizin "akılcı" kullanıldığı görülür ve bilinir olur.

1985 yılı öncesinde (dün), alınmış etik kararların içeriğinde, öncelikli seçim (triyaj), saptanmış "bitkisel hayat" ve "beyin ölümü" bilgilendirmeleri ağılıklı olarak yer alıyordu. Beyin ölümünün bitkisel hayat olmadığını anlatmakla geçen o yıllarda, organ bağışı konusuna giriş bile yapamıyorduk. Yoğun bakımların gelişimi ve vazgeçilmez bir disiplin haline gelişi, dünyada ve ülkemizdeki yoğun bakım yatak sayısındaki artışlar, transplantasyon cerrahisinde gelinen nokta ve organ bekleyen hastaların sayılarındaki artış, yoğun bakım etiğinin güncellenmesine yol açmıştır. Günümüz yoğun bakım etiğinde başı çeken başıkları öncelikli seçim, tedavileri dondurma/ sabitleme, tedavileri geri çekme, marjinal donör ve umudunu yitirmiş hastaların kalbi durmuşsa yeniden çalıştırmaya uğraşmayın (DNR) konuları ile sınırlandıralım. Son başlık için ülkemizde varılmış ortak bir görüş bulunmamaktadır. Öncelikli seçimin sosyal ve tıp toplumlarında ki kabullenme oranları oldukça yüksektir. Kalan başlıklardan, tedavileri dondurma ve geri çekme başlıklarının hasta yakınlarınca anlaşılma ve kabullenme olasılıkları düşüktür. Tıp eğitimi almış kişilerde bile anlaşılır olma konusunda güçlükler yaşadığımız için, konunun etik yönünü burada ele almıyorum. Yoğun bakım dışındaki bilim dallarında, "yapılacakların tümü yapıldı, yapılacak başka bir şey kalmadı" sözüne hiçbir taraftan itiraz gelmez iken, yoğun bakımda aynı cümlenin tıp kesimi dahil her kesimde fırtınalara yol açtığı görülmektedir. Bu seviyede aktarılacak bilgilendirmelere özen gösterilmeli ve bilimsel çerçeve dışına çıkılmamalıdır.

Yaşadığımız "aktif yaşam" bizi bir yerde "düşünsel yaşama" yöneltmelidir. Düşünsel yaşamımızın bize kattıkları ile "aktif yaşamı" daha verimli yaşarız. "Eylemsiz bir derin düşünce yaşamı kördür, derin düşüncesiz bir aktif yaşam da boş" diyen düşünürler, "vita activa" ile "vita contemplativa" arasında var olan kendiliğinden geçişli ilişkinin insanı mükemmelleştirdiğini ileri sürmektedirler (4). Hastalarımızda prognoz tahminleri yaparken, onların gelecekteki olası aktif ve düşünsel yaşamlarını da derin düşünsel yaşamımız içinde değerlendirdiğimizi ekip içinde sıkça tekrarlamalıyız. Kişisel deneyimlerimiz ve gözlemlerimizle elde ettiğimiz bilgi, bir başka deyişle epistemik açıdan üstün olan bilgi oranında, hastalarımızın prognozlarına gerçekçi tahminler yapabildiğimizi göstermeliyiz. Tahminlerimize derin düşünsel yaşamımızdaki birikimleri katıp, prognozun ayrıntılarına ulaşmaya çalışmalıyız. Etik kararlarımıza önce kendimiz ve ekibimiz ikna olmalıdır. Prognozun ayrıntılarını her zaman derin düşünce boyutunda irdelediğimizi belirtirken ne kadar inandırıcı olursak, etik kararlarımıza duyulacak güven o kadar fazla olur.

Yoğun bakım etiği bilgi, donanım ve deneyim artışlarına bağlı olarak değişim gösterebilir. Bu gelişmeler hastalarımızın yaşamalarını da doğrudan etkileyecektir. Bütün gelişmelere ve deneyimlerimizdeki artışa rağmen tüm hastalıkları tedavi edemeyeceğimizi kabul etmemiz gerekir. Elbette öleceğiz. Değişimleri yaşayarak, öğrenerek ve yapılması gerekenlerin tümünün yapıldığını bilerek öleceğiz. "Hayatı ölüm tanımlar ve ölümlerimiz anlamdan yoksunsa, hayatlarımızda yoksundur" der Octavio Paz (12). Yaşamlarımıza bir anlam katabildiysek, ölümlerimizi de anlamlı kılmaya odaklanmalıyız.

Yoğun bakımın etiğinde 1968 yılında bir "devrim" yaşanmıştır. Beyin ölümünün "ölüm" olarak kabul edilmesi ve organların bağışlana bilmesi, tıp etiği ve yoğun bakım etiğinin yeniden yazılmasını zorunlu kılmıştır. "Beyin ölümü" saptanmış ise organlarımızı bağışladığımızı belirten "bağış kartı", 1968 devriminin belgesidir. Dünyada başlamış ve çoğu ülkede geçerlilik kazanmış, ikinci devrimin belgesi "tıbbi vasiyetin", ülkemizde de geçerli olabilmesi için etik, hukuk, felsefe ve tıp disiplinlerinin bir araya gelerek başlattığı çalışmaların hızlanması ve yaygınlaşması gerekmektedir. Tıp eğitimine başladığımız 1968 yılında gerçekleşmiş devrimin 
ürünü olan "beyin ölümü" eğitimlerimizin her aşamasına damgasını vurmuştur. Bu eğitim ile bu günlere gelmiş bizim kuşağın bitirmek zorunda olduğu bir ödevdir "tıbbi vasiyet". Ödevimizi bitiremez isek, gelecek kuşağın eleştirmekten öte, bizden hesap sorma hakkı doğar.

Var sayalım yoğun bakıma alınmış ve tıbbi durumumuz ile ilgili alınacak kararlara katılamayacak durumdayız. Her gün bilgilendirme odasında hasta yakınlarına aktardığımız etik kararlarımızın onayını beklediğimiz bir anda ve hasta (BIZ) dışında herkesin söz sahibi olduğu bir ortamın içindeyiz. Kişiselleştirerek diyorum ki;

"Bir gün kendi geleceğime ilişkin alınacak tıbbi kararlara katılamayacak durumda olursam, düşünsel yaşamımı geri dönüşümsüz olarak kaybetmiş ve aktif yaşamım hiç olamayacak ise"

aşağıdaki beyanım ............ diye başlayan ve tamamladığım noter onaylı resmi belge mi görebilmek istiyorum. Bana düşen görev yerine getirilmiş ise, yoğun bakımın sorumlusu da görevini yerine getirir.
Komadayım

Beni tedavi etmeye çalışan yoğun bakım uzman ve ekibi prognozumu net olarak biliyor ve görebiliyor,

Önlerinde "tıbbi vasiyetim" duruyor,

Artık başka kimseye sorulmasın.

Zamanı boşuna tüketmeyin.

"Ölüm hoş geldi sefa geldi"

Che Guevara

Yaşamıma katabildiğim anlamı tam olarak ifade edemem ama ölümüme anlam katmak istiyorum.

Hakem Değerlendirmesi: Editörler kurulu tarafından değirlendirilmiştir.

Finansal Destek: Yazarlar tarafından finansal destek bildirilmemiştir. 


\section{Kaynaklar}

1. Feldman F. Etik Nedir? İstanbul: Boğaziçi Üniversitesi Yayınevi; 2012.

2. Deleuze G. Müzakereler. Istanbul: Inci Uysal; 2013.

3. Löhrs U. Patolojiye Etik. Tıbbın Gündelik Yaşamında Etik. Istanbul: 2001.

4. Han BC. Zamanın Kokusu. Istanbul, Metis; 2018.

5. Tutumlu MA. Zamana Baktım Petrarca. Ankara, Kaos Çocuk Parkı Yayınları; 2019.
6. Spinoza. Ethica. Istanbul: Alfa 2019.

7. Sağır A. Ölüm Sosyolojisi. Ankara: Phoenix Yayınevi 2014

8. Ökten KH. Ölüm Kitabı. Istanbul, Agora Kitaplığl; 2010.

9. Lyotard JF. Felsefe ve Eylem Üzerine. Uzun E, editor. Niçin Felsefe yaparız? Ankara, Pharmakon Yayınevi; 2016. p.109.

10. Nietzsche F. 185. Taş F, editor. Gezgin ve Gölgesi. Istanbul, Ithaki Yayınları; 2005. p.107.
11. Telci L. Ölmeden Ölüm. Saydam MB, KızItan $\mathrm{H}$, editors. Hekimin Filozof Hali. Istanbul, Ithaki Yayınları; 2018. p.78.

12. Octavio P. Ölümü Inkar Eden Bir Uygarlık. NPQ Türkiye 1994;8:32. 